\title{
SOCIAL INFRASTRUCTURE MODERNIZATION AS A PRIORITY REGARDING RURAL LIFE STANDARD IMPROVEMENT
}

At the present stage of socio-economic changes rural area economic activity conditions have changed in Russia, which has significantly worsened socialfacilities and engineering infrastructure effective functioning problem. The rural social infrastructure status has been recently deteriorating due to the lack of effective State support instruments and investments. In this paper, Russian rural social sphere development trends are considered, guidelines referred to the government control of rural area social sphere development are analyzed, methodology related to social facilities and engineering infrastructure efficient functioning is suggested as a determining factor for the agriculture labormarket efficient development. A conceptual model of rural area social infrastructure strategic development and a mechanism of management control organization and rural area social infrastructure development based on a comprehensive analysis are suggested.

Transformation of the Russian society in XXI century is associated with the general crisis of almost all spheres of life: economical, political, social and moral. The radical socio-economic transformations in Russia, their complexity and ambiguity, inconsistency and lack of scientific basis have exacerbated social problems of rural population: unemployment and poverty have increased; health and education materialtechnical base has outdated, the range of socio-cultural services has reduced; physical culture and sport are not developed; network of preschools is limited, etc. The existing social situation in rural municipalities expressed in agricultural labor depreciation and its development motivational mechanisms weakening and absence of socially acceptable living conditions approached the tolerance threshold and it hampers generation of socio-economic conditions for rural area sustainable development.

Over the past decades growth of negative changes in rural population's lifestyle and critical condition of rural social infrastructure as a whole has been observed, which is due to agricultural production sharp decline, rural financial situation worsening, breakup of old organizational-economic development mechanisms of rural social infrastructure and social protection, a significant backlog of rural municipalities compared to an urban level and living standards.

It is to be noted that rural municipalities are an inseparable part of Russian economy and complex multiproblematic objects of management. In the public mind, they continue playing the role of outlying territorial entities with lagging socioeconomic development and low level of living. Russia's transition to market economy caused the reforms of local government, including the level of rural municipalities. In the period of market relations formation and development a radical revision of rural municipalities' development strategic orientation should have social orientation. However, lack of experience and efficient scientific investigations in the field of rural socio-economic development strategic planning, allowing to link the multidirectional goals and ensure stable locally managed development, leads to certain negative consequences, elimination of which requires additional effort and material-production resources. 
Lack of a common economic algorithm of modernization, development and effective functioning of social facilities and engineering infrastructure suitable for market economy exacerbates the rural area life standard problem, also adversely affecting the workforce quality in agriculture.

Despite positive changes arising from the complex federal and regional social projects and programs implementation, the state of rural social infrastructure has been deteriorating in recent years. This is primarily due to the lack of state support and investment efficient instruments. Besides, due to the lack of unified concept for rural social sphere development not only as an independent institution, but in view of all factor interactions, ensuring its efficient functioning.

Significant difference between social and engineering infrastructure in urban and rural areas is due to sharp decline of rural social sphere and engineering infrastructure investments. Thus, total amount of investments into rural health care in Russia in 2009 made only $20 \%$ of the level of 1990s; and for cultural institutions and water supply system development has been allocated only $12 \%$ of the funds compared to 1990 level. The Federal Target Program (FTP) «Rural Social Development until 2010» made a positive impact only on the development of industries, financed from the federal budget (construction of housing, water supply networks and telephones installation).

In Soviet times, rural infrastructure and social sector objects as a determining factor in agriculture labor market effective development were an inseparable part of large collective and state farms. The objects of socio-economic infrastructure were owned and financed by agricultural enterprises. These enterprises provided not only agricultural production but also social service provision and development as well as village infrastructure maintenance. The majority of non-agricultural rural services and industrial structures were under their authority. In the framework of the general policy in construction, all efforts were concentrated on development of urban industrial areas. Systems of basic utilities, including water supply, sewerage, telecommunications, etc. were relatively well developed in both large and small towns, large settlements, but not in the rural area. In general, the rural social service level and infrastructure state are significantly lower than urban ones.

The transition period problems have negatively affected the social service system and rural infrastructure. Agricultural enterprises' arrear growth has led to «exhaustion» of these farms and service sphere reduction. The legislation passed in 1991-1992 years enabled the collective and state farms and their transferees to transfer their social assets to the balance of the relevant regional or local authorities. After such transferring the financing of costs for the social sphere objects management and maintenance became the responsibility of local and municipal authorities. The local authorities did not take any legally binding obligations concerning the maintenance of these objects. The main deterrent factor restraining transition of social objects is the lack of funds in local budgets [1].

As a result of reduced funding from traditional sources (agricultural governmental enterprises), federal budget and local municipality budgets, the state of rural social infrastructure is continuing to deteriorate. The number of children attending preschool institutions has decreased by 2,5 times over the past ten years (2009 to 1999), while the number of pupils in rural schools has increased by only $4 \%$ during this period. Compared to 1970 , in 2009 the number of educational institutions has decreased significantly. At present, further reduction in the number of cultural sites and cultural events is observed.

Despite some positive trends, possibilities of rural infrastructure and culture development are much limited due to financial problems in the country as a whole, as well as to general economic condition deterioration in rural areas. Over the past ten years sharp decline of investment into rural social and engineering infrastructure has been observed, the only exception is natural gas supply networks construction. Investments into rural health care in Russia in 2009 made only 19\% of the 1990's, and cultural institutions, into water system development have been allocated only $10 \%$ of funds from the 1990 level. This indicates that that the gap between urban and rural areas in the social and engineering infrastructure development is not narrowing but widening, and Russia, perhaps, will be increasingly lagging behind rural infrastructure international level. The Federal Target Program "Rural Social Development till 2012" has had positive impact only in the development of industries, financed from the federal budget (construction of housing, water supply networks and telephones installation) [2].

The rural social sphere actual trends and development analysis gives disappointing conclusions. Inefficiency of agrarian relations transformation in terms of motivation mechanisms and life standard improvement is apparent. The social factor has become the obstacle to agricultural production development and efficiency. The social sphere now as never before is hemmed in by the growing contra- 
dictions: on the one hand, it is an objectively increasing need for operation and development funds; on the other hand, the actual steady decline in their income.

To overcome the crisis of rural social and labor sphere and implement art. 7 of the Constitution declaring that the policy of the Russian welfare state is aimed at creating conditions for a dignified human life, the approach to rural development must be radically changed. Rural area is not only agricultural industrial sphere, but socio-territorial subsystem of the society performing a wide range of functions (demographic, workforce supply, cultural and others) as well.

Rural development should be based on optimal combination of government regulation and market self-adjustment, clear bordering of power and responsibility of federal budget, subjects of the RF budgets, local budgets, and extra budgetary funds, funds of legal and natural persons engaged for the social programs implementation.

This comprehensive approach to problem resolution of rural resettlement will allow minimizing investmentsinto social and engineering infrastructure development through local differentiated solutions according to a type of a rural settlement, number and age structure of the resident population, availability of transport and telecommunication infrastructure.

The national project "Agro-Industrial Complex Development" currently in force is the basis for the medium-term state agricultural development program formation and rural life standard conditions creating.

The national project "Agro-Industrial Complex Development" is the primary level, for the period of which the Russian Federation Government decision from July 14, 2007 № 446 has been approved the State Program of agriculture development and agricultural product raw materials and food markets regulation for 2008-2012. That is designed in accordance with Article 8 of the Federal Law "On the Development of Agriculture".
In the framework of the Programme fulfillment the main areas related to the effective functioning of social facilities and engineering infrastructure are:

1. creating preconditions for sustainable development of rural areas and ensuring better living conditions in rural areas by the year 2012 (an increase in 2009 housing input in 3,7 times more than in 2008);

2. increasing supply of rural population with drinking water to $66 \%$, and the level of natural gas supply - up to $60 \%$ due to rural social and engineering infrastructure reconstruction and capacity building, staffing and information management improvement.

With successful implementation of the above directions of the Program the following dynamics of rural social and engineering infrastructure development is planned (table 1).

The FTP total resource supply from the Federal budget in view of its prolongation till 2012 is increasing (in actual prices of the year, taking into account projected inflation) to 93,8 billion rubles, including 30,6 billion rubles, or 2,6 times as much in 2008-2010; including for housing - 2,5 times, for water supply improvement $-4,8$ times, for gasification development $-2,1$ times as much.

Resource provision increase allows enhancing significantly the target indicators and the FTP indicators. Thus, for 2008-2010 it is planned to purchase 1,3 times more housing for rural residents, including young families and young professionals in rural areas, which is more than 1,8 times as much; drinking water supply - up to $66 \%$ (versus $47 \%$ ), and house (apartment) gasification rate - up to $60 \%$ $(48,6 \%)$.

Taking into account the main directions of the government policy in rural social sphere development, methodological regulations for effective functioning of social facilities and engineering infrastructure as a determining factor in the agricultural labor market effective development should be based on the following basic principles:

Table 1

The dynamics and forecast of social sphere development in 2008-2012 years

\begin{tabular}{|c|c|c|c|c|c|c|}
\hline \multirow{2}{*}{ Indicators } & \multirow{2}{*}{ Units } & \multicolumn{5}{|c|}{ Years } \\
\hline & & 2008 & 2009 & 2010 & 2011 & 2012 \\
\hline $\begin{array}{l}\text { 1. Input and acquisition of housing for residents } \\
\text { living in rural areas, young families and young } \\
\text { professionals - total }\end{array}$ & thousand $\mathrm{m}^{2}$ & 1489,2 & 2861 & 3325,9 & 3963,2 & 4039,1 \\
\hline $\begin{array}{l}\text { - Including measures for ensuring affordable } \\
\text { housing for young families and young professionals } \\
\text { in rural areas }\end{array}$ & thousand $\mathrm{m}^{2}$ & 647,1 & 1212,1 & 1482,4 & 1832,9 & 1890,7 \\
\hline 2. Provision of rural population with drinking water & $\%$ & 45,9 & 49,4 & 54,9 & 60,7 & 66,3 \\
\hline $\begin{array}{l}\text { 3. The level of gasification of houses (apartments) by } \\
\text { gas network }\end{array}$ & $\%$ & 43,6 & 47,1 & 51,0 & 55,5 & 59,9 \\
\hline
\end{tabular}


- creating equal conditions for access to welfare services for all categories of the population;

- promotion of quality livelihood strategies through a balanced socio-economic development based on rational use of natural resources;

- planning of rural social sector development focused on the process, that is an interactive planning with adjustments depending on the prevailing trends;

- degree of rural services, social facilities and engineering infrastructure supply is assessed through the quality and standard of living rates of the present generation with a glance to increase the given rates for future generations.

The dynamic and qualitative development of the social sphere in rural areas is a new factor of growth not only productivity, but also agricultural production in general.

The concept of rural social infrastructure strategic development should be based on socio-economic development of priority determination to the level of rural areas, analysis of the residents' needs and expectations, acquired level of development and state of social infrastructure. There should be a forecastanalysis document including a system of strategic choice measures, objectives and priorities of social infrastructure modernization, taking into account the existing variety of resources and mechanisms for its implementation over time. Accordingly, formulation of the rural area social infrastructure strategic development concept assumes implementation of a particular model (Figure 1).

The purpose of the rural area social infrastructure strategic development concept is to identify key rural community development issues and development of economic, legal, administrative and managerial measures aimed at rural poverty reduction and life standard increase. [3]

Rural Area Social Infrastructure Strategic Development Conceptual Model development and implementation plays a key role in ensuring social process efficiency and quality and standard of living improving which is shown in the following:

1. The developed Rural Area Social Infrastructure Strategic Development Conceptual Model ensures the mechanism of implementation of long-term investment related to rural population's life standard improvement as well as socio-economic development of the territory as a whole and its individual structural units;

2. The Strategic Development Conceptual Model allows predicting changes in external and internal environment factors in advance and to minimize their negative impact on functioning and development of social infrastructure as a whole and its individual components in particular;
3. Social infrastructure development strategy development and implementation allows identifying and using an internal investment potential for social sector development and rural population's life style improvement;

4. Social Infrastructure Strategic Development Conceptual Model development and implementation allows identifying and using an internal investment potential of an agrarian region for social sector development and rural population's life style improvement;

5. Social Infrastructure Strategic Development Conceptual Model development and implementation allows determining comparative competitive advantages of rural municipalities in line with other rural areas;

6. Availability of Rural Municipalities Social Infrastructure Strategic Development Conceptual Model provides a clear linkage of strategic and tactical management of social processes in rural areas.

High dynamics of key macroeconomic indicators, scientific and technological progress pace, investment market frequent fluctuations do not allow management, let alone development of the rural social sphere together with its infrastructure, only on the basis the cumulated past experience and traditional management practices. Necessity and urgency of developing a rural area social infrastructure strategic development conceptual model is determined by a number of conditions, most importantly, the intensity of external and internal environment influence factors. That is why, in our view, the development of rural area social infrastructure strategic development conceptual model on the basis of the strategic management theory best fits the current conditions in the countryside and the need of lifestyle quality improvement and developing the territory as a whole.

An essential tool for strategy development of any economic system is information, without which today there cannot be rural population efficient economic management, social sector and infrastructure development and lifestyle quality improvement. Control is to be organized and implemented in present rural area social infrastructure processes because of the following reasons:

- environment instability increase requires additional management system requirements and level of social infrastructure development;

- shift from control of the past to the analysis of the future state;

- an urgent need to increase the rate of reaction to changes in external environment, improving flexibility of management, expansion of 


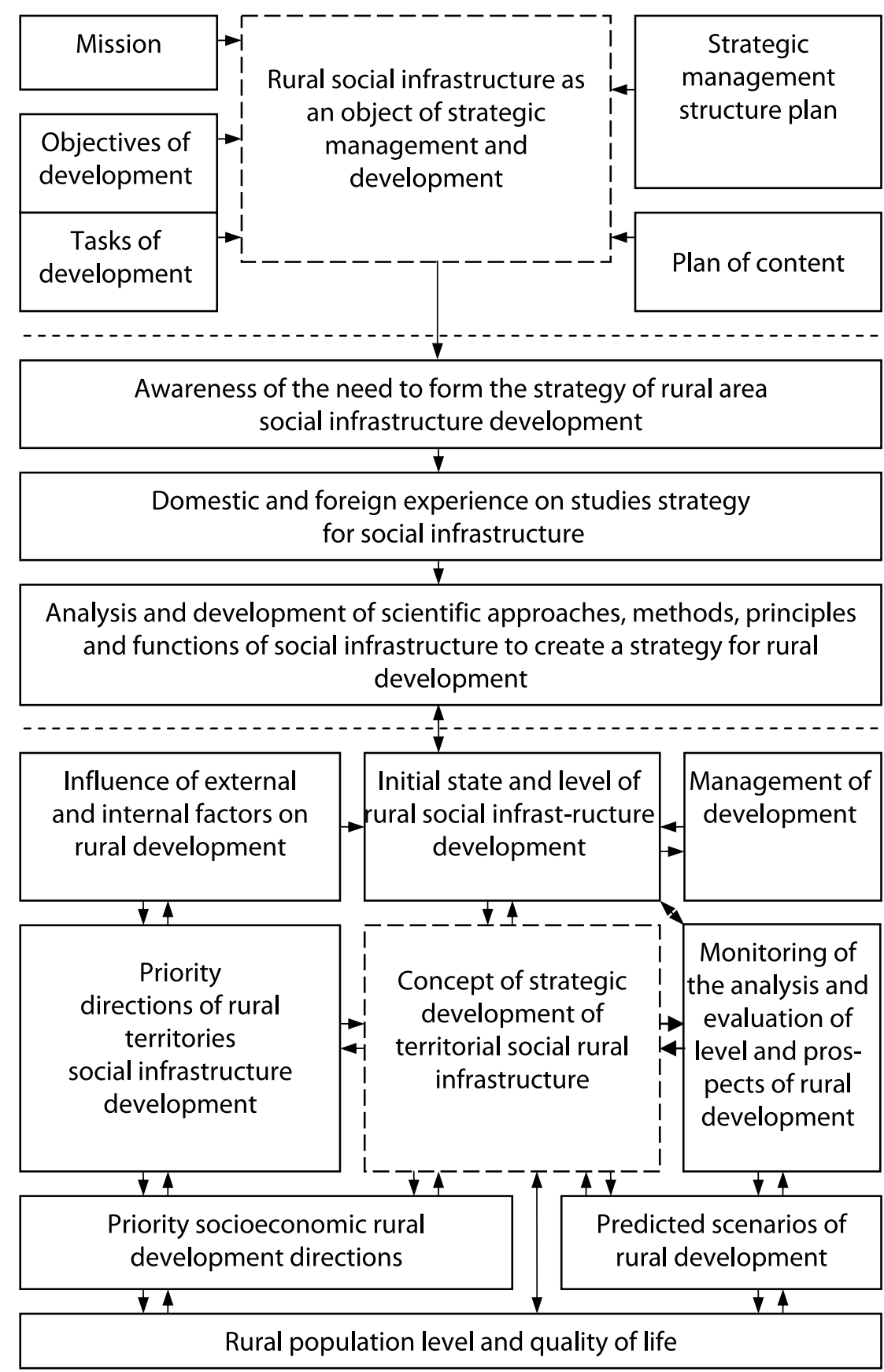

I level of the model: THEORETICAL

Purpose - formation of theoretical foundations rural social infrastructure of strategic development

Il level of the model: METHODOLOGICAL

Purpose - development of methodological basis for generation of the rural area social infrastructure strategy

III level of the model: CONCEPTUAL AND METHODICAL

Objective - generation of a concept of rural social infrastructure strategic

development adapted to market

conditions and aimed at rural population life quality increasing

Fig. 1. Conceptual model of strategic development of social infrastructure of rural areas

social infrastructure development directions and continuous monitoring of changes within the rural social infrastructure;

- need for clear and motivated system of actions on functioning of social infrastructure to meet maximum requirements of the population and avoid crisis situations;

- complication of the management system, expansion of areas for strategic development of social infrastructure and complexity of internal processes requires a coordination mechanism within the very social infrastructure;
- general cultural tendency to synthesize, integrate different areas of knowledge and human activity.

Thus, social infrastructure functioning and development control in rural areas is the set of strategic management mechanisms: accounting, planning, analysis, forecasting and control, combined at a qualitatively new stage of market relations development into a single system operating according to a specific purpose. A schematic mechanism of controlling, providing a qualitatively new level of organization and social infrastructure management in rural areas is shown in figure 2. 
The purpose of controlling is management process orientation at achieving all the objectives of rural area social infrastructure operation and development, in particular, improving rural population life standards

\section{Main tasks:}

- Rural diverse resources and potential conservation and priority use in the process of social infrastructure management and development goal achievement;

- Timely adaptation to rural area internal and external environment and social infrastructure changes,

- Creating conditions for social infrastructure sustainable operation, market relations conditions maximizing, as well as rural population life standard improvement.

Progress analysis and adjustment in accordance with the objectives: social infrastructure assessment to achieve the goals

Controlling system:

automation: processes controlling efficiency

Controlling introduction is application of functions, methods, instruments for controlling the following areas:

- Changes in social infrastructure management;

- Changes in social infrastructure organizational structure;

- Information flow formation;

- Life quality and possible problems

Monitoring and identification of social infrastructure management problems: collection, processing, analysis and indicators of social infrastructure current state

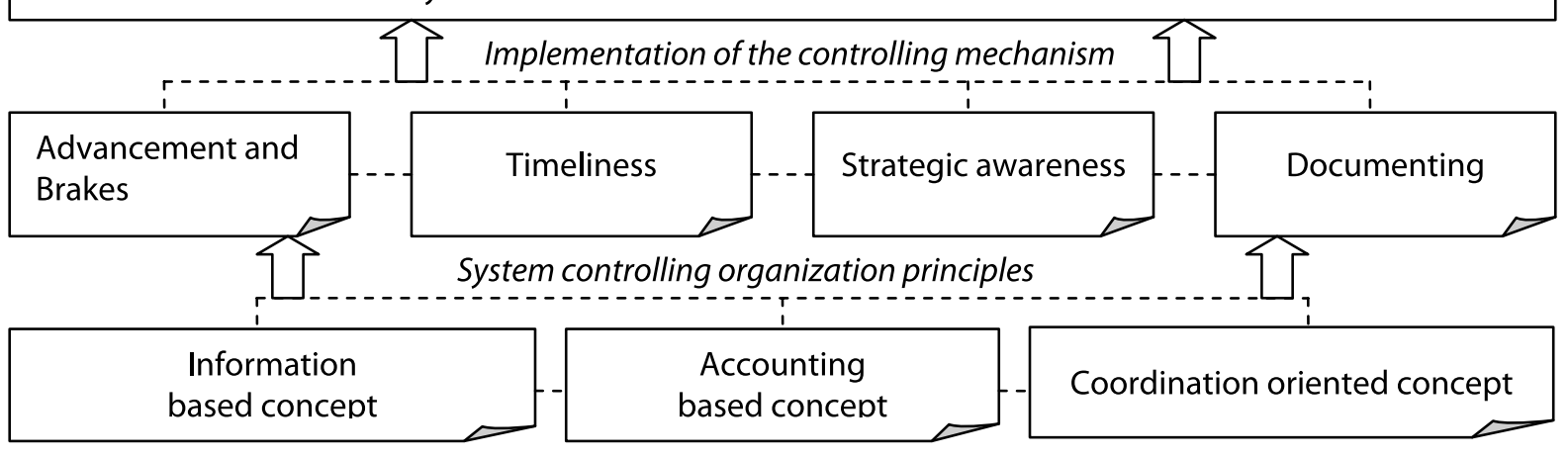

Concepts of controlling

Fig. 2. The mechanism of controlling the organization management social infrastructure development in rural areas

Controlling is a system of rural infrastructure social development management aimed at meeting immediate demand by people in a short term, improving quality life standards of the rural population in a long term [4].

Introduction of controlling into the process of social management is associated with formation of market relations and their penetration into all the spheres of public life, competition strengthing, population's needs and demands for services and quality of life increasing, the need of taking into account integrated social and economic factors in shaping the strategy of socio-economic development of municipalities. There may be the following results of introduction of controlling:

1. enhancing the role of public administration and social infrastructure development through the introduction of information and communication technologies;

2. increased informational transparency of public authorities, their interaction with population and social infrastructure organizations;

3. creating an effective information system that provides an opportunity for making optimal management decisions in the social sector at municipal and regional levels; 
4. improving the quality and timeliness of decision implementation, reducing time spent on searching, processing, transmission and provision of data needed;

5. ensuring accuracy and timeliness of receiving the necessary information on status and level of social infrastructure development, life quality, its streams reuse of data managing.

Nowadays in Russia formed the basis for widespread controlling introduction is being formed. The practical implementation of rural area organization management and social infrastructure development controlling mechanism is impossible without using up-to-date informational and computer technologies. Controlling automation has its duration, milestones, risks and its effect.

This direction is very complex and affects the whole system of social sphere management. Implementation of the proposed recommendations will contribute to achieving the strategic goals and objectives of rural area social infrastructure development, rural population life quality improvement and developing their territories as a whole.

Rural area social infrastructure upgrading leads to improvement of labor resources reproduction processes in agricultural sphere, as well as to life standards improvement. Targeting the ensuring of social sphere effective functioning provides the use of labor territorial mobility as the most cost-effective form of achieving agrarian labor market balance.

\section{References}

1. Ovchintseva L. A. Social infrastructure of the village in the context of sustainable development of rural areas // Sustainable development of rural areas: concepts and mechanisms. M., 2001. P. 368-375

2. Maksutov L. G. Social component in the planning of rural development // Models of rural areas socio-economic development indicative planning // Russian Scientific - Research Institute of Economics and Standards. Rostov-on-Don, 2006. P. 162-164.

3. Kostarev A. V., Pytkin A. N. Features of the formation and development of social infrastructure of rural municipalities in connection with the transition to market relations. Booklet. Perm: Publ. NIIUMS, 2003.

4. Kostarev A. V. The current state of rural social infrastructure and the reasons hindering its development // Russian scientific-practical conference Materials "Reforming the system of public finance management in a region: Theory and Practice" - Perm, 2004. 